Case Report

\title{
Epinephrine Injection Associated Scrotal Skin Necrosis
}

\author{
Murat Gul, ${ }^{1}$ Mehmet Kaynar, ${ }^{2}$ Tamer Sekmenli, ${ }^{3}$ Ilhan Ciftci, ${ }^{3}$ and Serdar Goktas ${ }^{2}$ \\ ${ }^{1}$ Department of Urology, Van Training and Research Hospital, 65100 Van, Turkey \\ ${ }^{2}$ Department of Urology, Selcuk University School of Medicine, Turkey \\ ${ }^{3}$ Department of Pediatric Surgery, Selcuk University School of Medicine, Turkey
}

Correspondence should be addressed to Murat Gul; drgulacademics@gmail.com

Received 14 April 2015; Accepted 14 June 2015

Academic Editor: Ferdinando Fusco

Copyright (C) 2015 Murat Gul et al. This is an open access article distributed under the Creative Commons Attribution License, which permits unrestricted use, distribution, and reproduction in any medium, provided the original work is properly cited.

Male circumcision is among the most frequent surgical interventions throughout history. Although considered as a minor intervention, it may have complications ranging from insignificant to catastrophic. These complications can be attributed to the surgical procedure and anesthesia. In this report we present two cases of scrotal skin necrosis after lidocaine with epinephrine injection using subcutaneous ring block technique prior to circumcision.

\section{Introduction}

Male circumcision, excising of the foreskin of penis, for traditional, religious, medical, or personal reasons is the most frequently applied surgical procedure in history. Although it can be considered as a minor surgery, it may lead to complications ranging from insignificant to catastrophic [1]. These complications can be attributed to both surgical procedure and anesthesia.

Today, circumcision is performed using several local anesthetic techniques such as caudal epidural block [2], dorsal penile nerve block (DPNB) [3], subcutaneous ring block (SRB) [4], and topical anesthesia applications [5]. We present two cases of scrotal skin necrosis after lidocaine with epinephrine injection using SRB technique prior to circumcision.

The guardians of both cases reviewed the case report and gave their written consent to the corresponding author for publication of the present report.

\section{Case 1}

A 2-year-old toddler was referred to our clinic with micturition complaints. His physical examination revealed phimosis and immediate circumcision was decided. Blood test was normal (PT, PTT, and INR). Prior to circumcision, local anesthesia was performed with lidocaine $1 \%$ containing epinephrine 1:200,000 subcutaneously using subcutaneous ring block anesthesia technique by a 27 -gauge conventional Tuberculin Syringe. On the 5 th postoperative day the patient was brought into the clinic with a crusty wound just below the penoscrotal junction. Conservative wound management was attempted using I.V. antibiotics and anti-inflammatory treatment. Sterile culture from the site of necrosis was obtained (Figure 1(a)). However, surgical intervention was decided when the site of necrosis enlarged one week later. Under laryngeal mask anesthesia necrotic lesion and tissue were excised and incision closed vertically (Figure 2(a)). During the control on the 6th postoperative day, it was seen that the patient's wound healed completely without any complication.

\section{Case 2}

A one-year-old toddler was admitted to our clinic with micturition complaints as in case 1 (Figure 1(b)). His circumcision was made using the same local anesthetic drug and technique. After 4 days patient was brought in with a fallen shell wound just below the penoscrotal junction. In this case, no conservative management was attempted and the second surgery was performed immediately. His wound also healed completely without any complication (Figure 2(b)). 


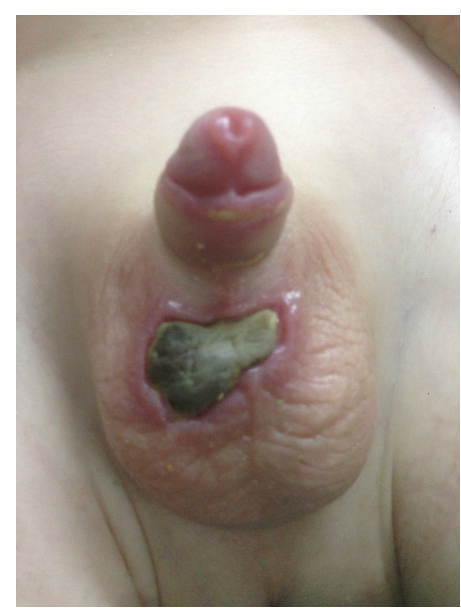

(a)

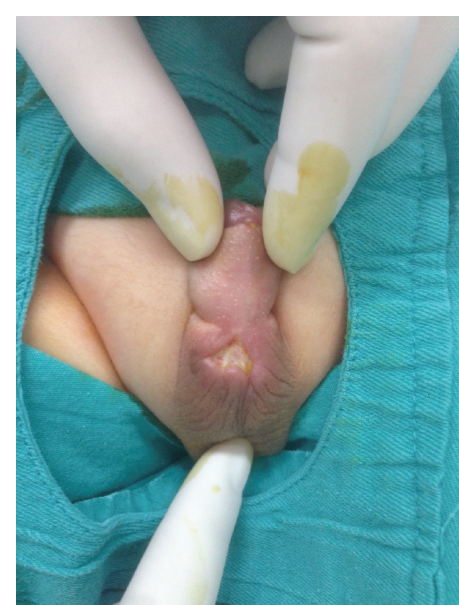

(b)

FIGURE 1: (a) Skin necrosis with a crusty wound just below the penoscrotal junction following lidocaine injection in case 1. (b) Skin necrosis with a fallen shell wound just below the penoscrotal junction following lidocaine injection in case 2.

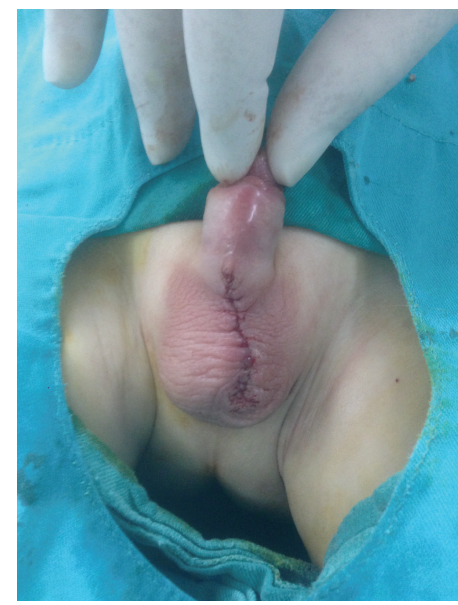

(a)

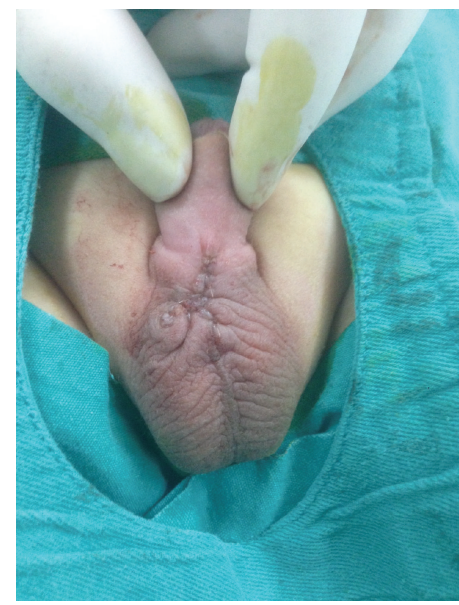

(b)

Figure 2: (a) Appearances of case 1 and (b) case 2 following second surgery.

\section{Discussion}

Circumcision indisputably is worldwide the most frequently performed minor male surgery [6]. Like any other surgical intervention, circumcision may have complications related to either surgery or anesthesia. These are bleeding, infection, skin bridge, urinary retention, meatitis, chordee, lymphedema, fistulas, and necrosis. Among these, the most common ones are easily handled bleeding and infections. But sometimes serious complications need surgical or reconstructive interventions [7]. In the relevant departments, within the last five years around 500 circumcisions were performed without major complications.

Necrosis following circumcision is a rare complication of glans penis due to infection, local anesthesia solutions with epinephrine, tight dressing, and reckless cauter use [8]. In the present cases skin necrosis developed on 5th and 4 th postcircumcision day, respectively. Local anesthesia containing epinephrine is considered to be the underlying reason. There are some contradictory reports about the usage of epinephrine combined with or without lidocaine using SRB technique for circumcision. Epinephrine use for penile block is considered to be contraindicative. Actually a vast number of studies reported penile block without epinephrine [9]. On the other hand, there are some large series that have reported the safe use of epinephrine $[10,11]$.

More recent studies showed that penis has a more complicated vascular system than earlier considered and less terminal vessels. Hence, epinephrine combined with lidocaine use has been considered as a safe SRB technique prior to circumcision [9]. Therefore, today epinephrine administration with local anesthetics has regained wide currency. Besides, due to the ease of use and prolonged postoperative pain control local anesthesia combination was preferred in the present cases. Previously, no scrotal skin necroses were experienced. 
Circumcision might be performed with different local analgesic applications than the one described previously. These are topically applied lidocaine-prilocaine cream, dorsal penile nerve bloc (DPNB), and SRB. Yet, there are some reports that topical use of lidocaine-prilocaine and DPNB with prilocaine may lead to methemoglobinemia $[5,12]$. Lidocaine usage on skin may also result in some complications including skin redness, rash, dry skin, blister, contact, and exfoliative dermatitis [13].

Normally SRB is defined as a subcutaneous circumferential ring injection of local anesthetic at the mid shaft of penis and SRB with lidocaine was shown to be the most effective anesthetic technique through all stages of the circumcision [14]. Therefore in our clinics this technique is preferred and applied as in these two cases. To our best knowledge, these are the first scrotal skin necrosis cases developing after local anesthetics' injection for circumcision analgesia. Therefore in the first case a conservative approach was attempted with I.V. antibiotics and anti-inflammatory treatment. However, the site of necrosis enlarged and limited itself but did not show any sign of healing. Eventually necrotic site was removed and complete recovery achieved after second surgery. Our experience with the first case made us avoid conservative treatment attempt and move on with the second surgical intervention.

\section{Conclusion}

Although circumcision using epinephrine is considered as a safe and painless procedure, epinephrine injection associated scrotal skin necrosis of the injection site should not be disregarded. Hence, general anesthesia with caudal blocks for postoperative pain relief can be considered in appropriate cases.

\section{Disclosure}

This report was previously presented partially at the $23 \mathrm{rd}$ National Urology Congress in 2014.

\section{Conflict of Interests}

Murat Gul, Mehmet Kaynar, Tamer Sekmenli, Ilhan Ciftci, and Serdar Goktas reported no conflict of interests.

\section{Authors' Contribution}

Murat Gul, Mehmet Kaynar, Tamer Sekmenli, Ilhan Ciftci, and Serdar Goktas approved the final paper.

\section{References}

[1] S. Barnes, J. Ben Chaim, and A. Kessler, "Postcircumcision necrosis of the glans penis: gray-scale and color Doppler sonographic findings," Journal of Clinical Ultrasound, vol. 35, no. 2, pp. 105-107, 2007.

[2] A. E. May, J. Wandless, and R. H. James, "Analgesia for circumcision in children. A comparison of caudal bupivacaine and intramuscular buprenorphine," Acta Anaesthesiologica Scandinavica, vol. 26, no. 4, pp. 331-333, 1982.
[3] M. G. Soliman and N. A. Tremblay, "Nerve block of the penis for postoperative pain relief in children," Anesthesia and Analgesia, vol. 57, no. 4, pp. 495-498, 1978.

[4] L. M. Broadman, R. S. Hannallah, A. B. Belman, P. T. Elder, U. Ruttimann, and B. S. Epstein, "Post-circumcision analgesia. A prospective evaluation of subcutaneous ring block of the penis," Anesthesiology, vol. 67, no. 3, pp. 399-402, 1987.

[5] A. R. Kumar, N. Dunn, and M. Naqvi, "Methemoglobinemia associated with a prilocaine-lidocaine cream," Clinical Pediatrics, vol. 36, no. 4, pp. 239-240, 1997.

[6] C. P. Nelson, R. Dunn, J. Wan, and J. T. Wei, "The increasing incidence of newborn circumcision: data from the nationwide inpatient sample," Journal of Urology, vol. 173, no. 3, pp. 978-981, 2005.

[7] G. W. Kaplan, "Complications of circumcision," Urologic Clinics of North America, vol. 10, no. 3, pp. 543-549, 1983.

[8] N. Sterenberg, J. Golan, and N. Ben-Hur, "Necrosis of the glans penis following neonatal circumcision," Plastic and Reconstructive Surgery, vol. 68, no. 2, pp. 237-239, 1981.

[9] S. M. Schnabl, N. Herrmann, D. Wilder, H. Breuninger, and H. M. Häfner, "Clinical Results for use of local anesthesia with epinephrine in penile nerve block," Journal der Deutschen Dermatologischen Gesellschaft, vol. 12, no. 4, pp. 332-339, 2014.

[10] H.-M. Häfner, M. Röcken, and H. Breuninger, "Epinephrinesupplemented local anaesthetics for ear and nose surgery: clinical use without complications in more than 10,000 surgical procedures," JDDG-Journal of the German Society of Dermatology, vol. 3, no. 3, pp. 195-199, 2005.

[11] P. Sylaidis and A. Logan, "Digital blocks with adrenaline. An old dogma refuted," The Journal of Hand Surgery-British Volume, vol. 23, no. 1, pp. 17-19, 1998.

[12] H. Ozdogan, S. Osma, G. B. Aydin, A. Dinc, and G. Ozgun, "Methemoglobinemia presenting in a circumcised baby following application of prilocaine: a case report," Journal of Medical Case Reports, vol. 4, article 49, 2010.

[13] J. K. Aronson, Meyler's Side Effects of Drugs Used in Anesthesia, Elsevier, New York, NY, USA, 2008.

[14] J. Lander, B. Brady-Fryer, J. B. Metcalfe, S. Nazarali, and S. Muttitt, "Comparison of ring block, dorsal penile nerve block, and topical anesthesia for neonatal circumcision: a randomized controlled trial," Journal of the American Medical Association, vol. 278, no. 24, pp. 2157-2162, 1997. 


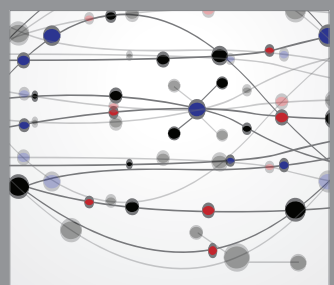

The Scientific World Journal
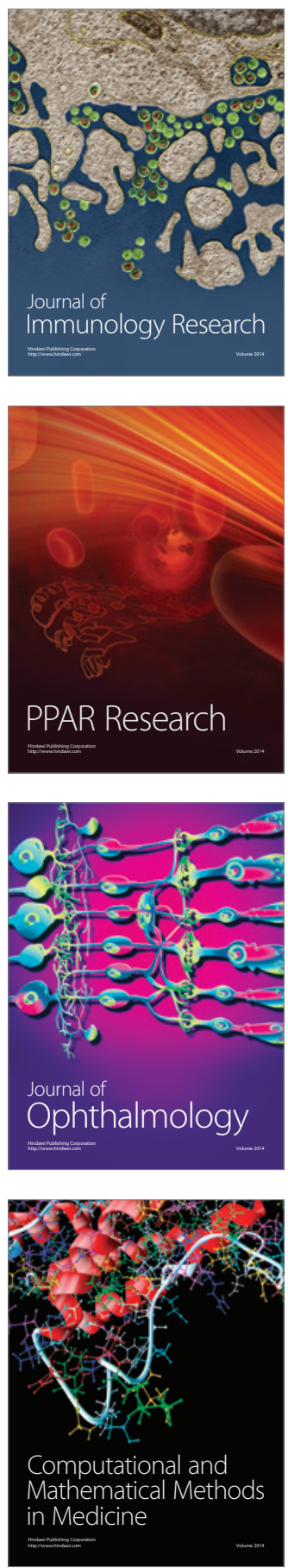

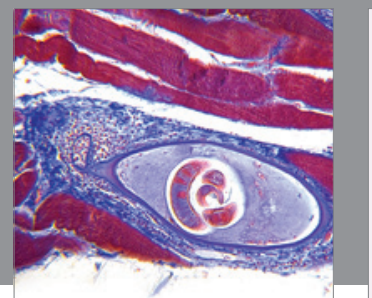

Gastroenterology

Research and Practice
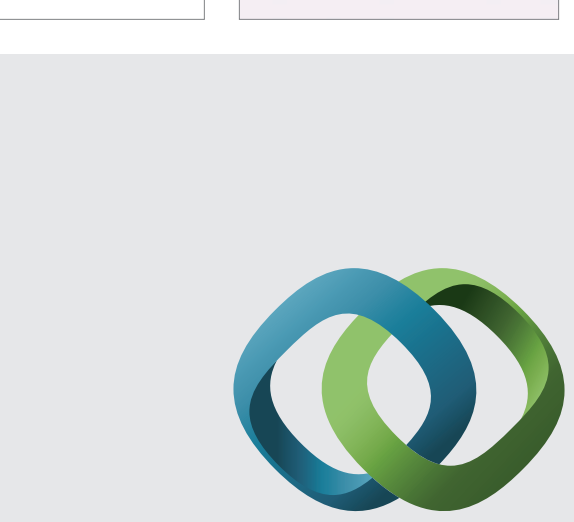

\section{Hindawi}

Submit your manuscripts at

http://www.hindawi.com
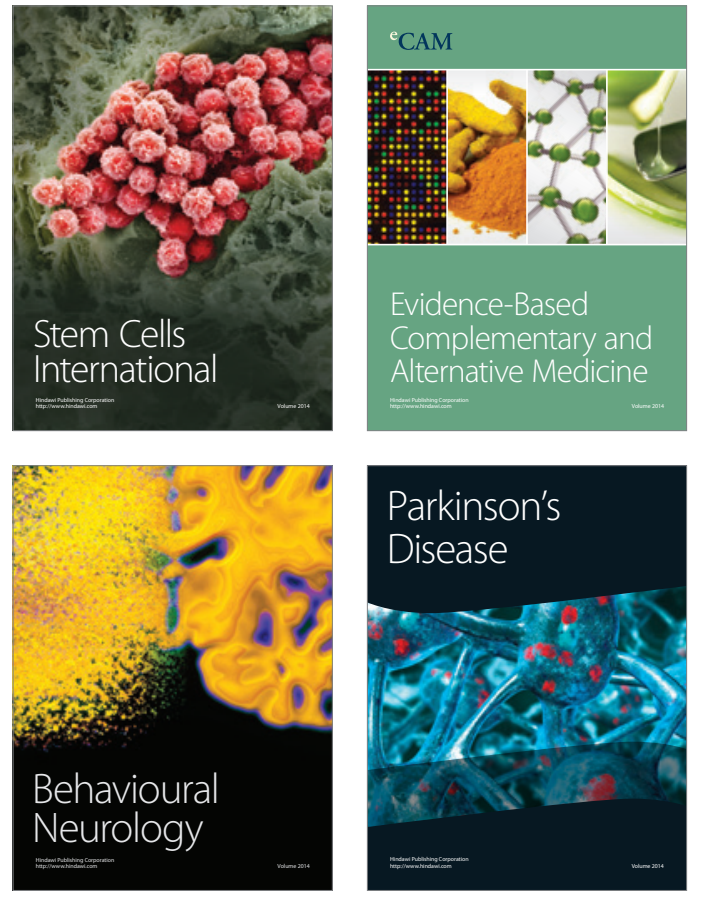
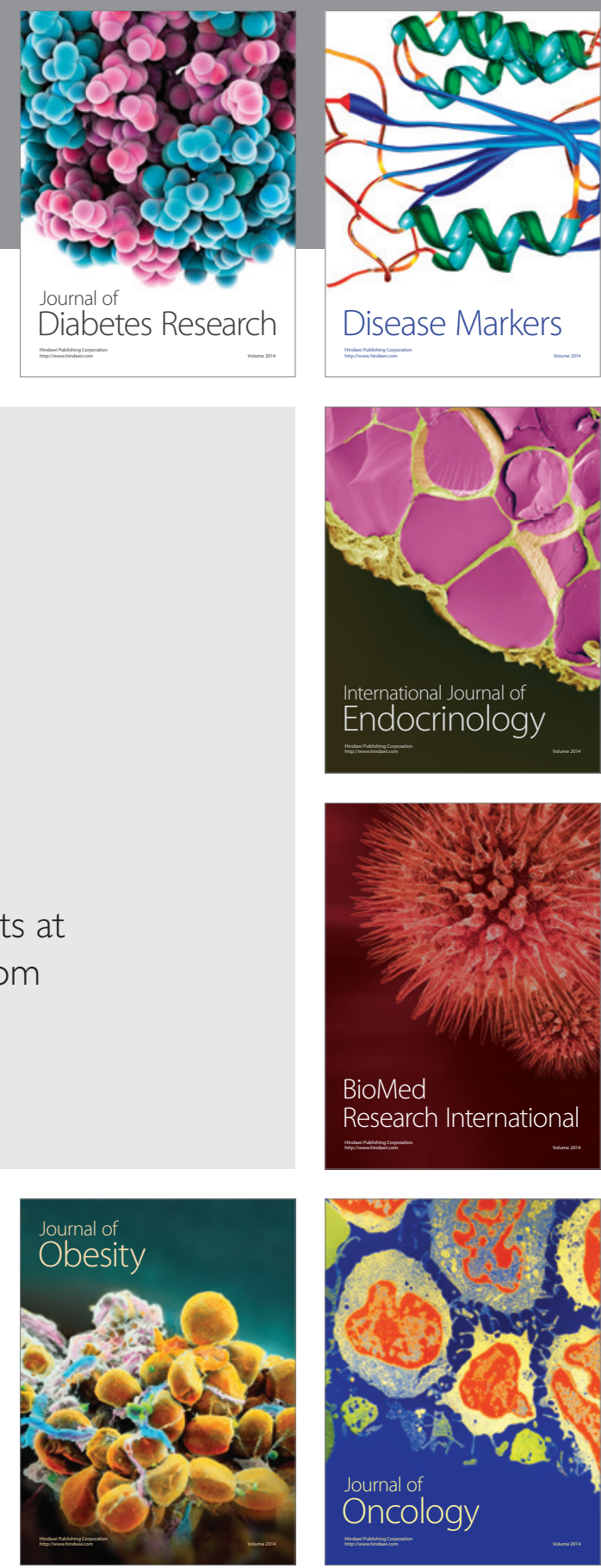

Disease Markers
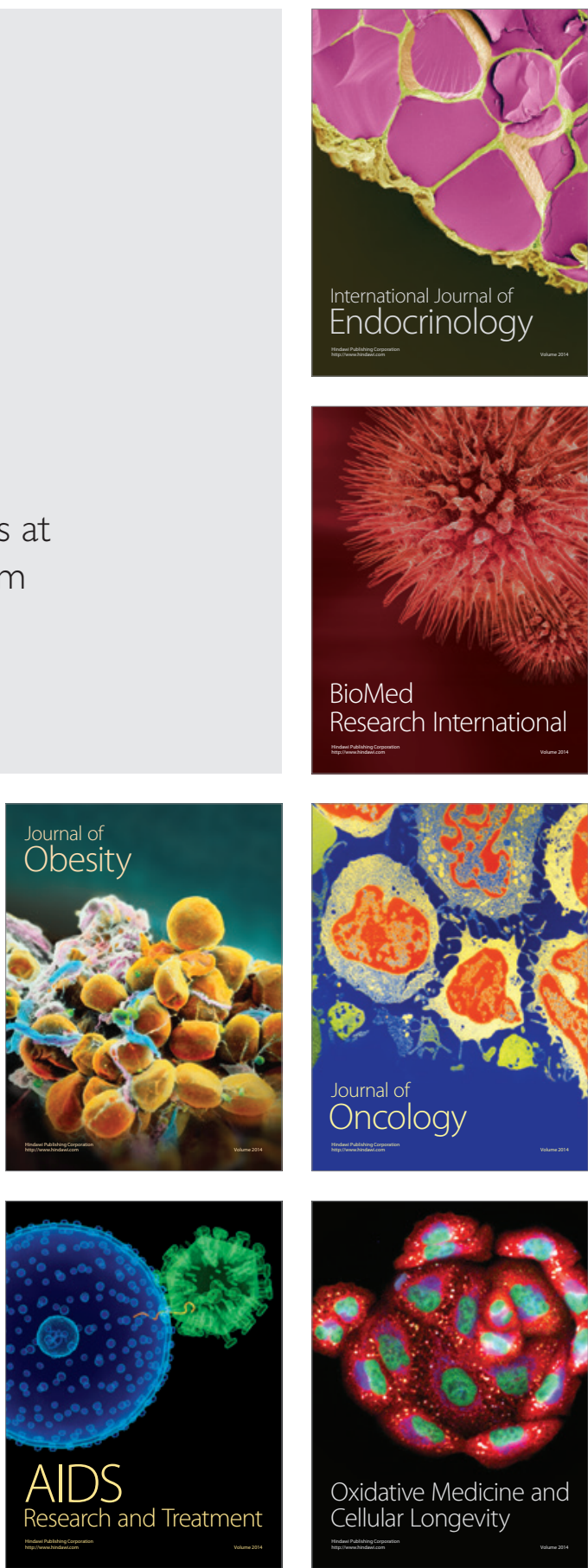